\title{
Studi Kurikulum Ilmu Sosial (IPS) di Sekolah Dasar di Indonesia, Malaysia dan Hongkong
}

\section{A Study of Curricula Social Science's (IPS) on Elementary Schools in Indonesia, Malaysia and Hong Kong}

\author{
Sriyanto \\ Universitas Muhammadiyah Purwokerto \\ Alamat email: sriyanto1907@gmail.com
}

\begin{abstract}
ABSTRAK
Berdasarkan asumsi filosofis, studi banding subyektif tidak memandang realitas sebagai objek tunggal. Masalah epistemologis dan aksiologi menjadi pertimbangan penting dalam pendidikan komparatif. Mengetahui perbedaan dan perbandingan sistem eduational antara negara-negara ini dimaksudkan untuk mengetahui beberapa isu yang harus dipertimbangkan untuk sistem pendidikan. Sadar atau tidak sadar perbandingan yang dilakukan oleh manusia dalam hidup dan pengembangan pribadi, melalui citra diri dengan merefleksikan aspek kehidupan yang sama dari orang lain. Studi perbandingan pendidikan sebagai bagian dari bidang pendidikan memiliki manfaat faktual, terutama sebagai pertimbangan untuk meningkatkan kualitas pendidikan di suatu negara. Dengan mempertimbangkan dan mempelajari keuntungan dari sistem pendidikan di negara-negara lain, seseorang dapat belajar banyak hal dari negara dan menggunakannya untuk kemajuan pendidikan di negara ini. Tujuan dari makalah ini adalah untuk melakukan studi banding ilmu sosial (IPS) di sekolahsekolah dasar di Indonesia, Malaysia dan Hong Kong. Berdasarkan sejarah-sosiologi, tiga negara memiliki kemajuan yang berbeda dalam pendidikan, Indonesia dulunya collony Belanda, Malaysia dan Hong Kong yang sebelumnya koloni Inggris. Melalui pendekatan komparatif antara negara-negara, peningkatan pendidikan langsung atau tidak langsung akan memberikan manfaat untuk meningkatkan pendidikan nasional dan mudah-mudahan akan mengambil nilai positif dari negara-negara tertentu untuk mendukung upaya dalam meningkatkan kualitas edutaion nasional.
\end{abstract}

Kata kunci: perbandingan, ilmu sosial (IPS), sekolah dasar, Indonesia, Malaysia, Hong Kong.

\section{ABSTRACT}

Based on philosophical assumptions, comparative study subjectively does not perceive the reality as a single object. Epistemological issues and axiology become a crucial deliberation in comparative education. Knowing the differences and the comparisons of eduational system among countries is intended to find out some issues to be considered for educational system. Consciously or unconsciously comparison is done by human in lifetime and personal development, through the selfimage by reflecting the same life aspect of the others. Comparative study of education as a part of education field has factual benefits, particularly as a consideration to improve the quality of education in a country. By concidering and studying the advantages of educational systems in other countries, one can learn many things from the country and use it for the progression of education in this country. The purpose of this paper is to conduct a comparative study of social science (IPS) in elementary schools in Indonesia, Malaysia and Hong Kong. Based on historic-sociology, the three countries have different progress in education, Indonesia was formerly a Dutch collony, Malaysia and Hong Kong were formerly British colony. Through comparative approach among countries, the educational 
improvement directly or indirectly will provide benefits to escalate national education and hopefully will take positive value from certain countries to support the attempt in raising the quality of national edutaion.

Keyword: comparative, social science (IPS), elementary school, Indonesia, Malaysia, Hong Kong.

\section{PENDAHULUAN}

Sejak lahir manusia tidak dapat dipisahkan dengan manusia lain. Tanpa hubungan sosial dan bantuan dari anggota keluarga lain, anak tidak akan berdaya dan tidak mampu berkembang menjadi manusia dewasa. Selanjutnya dalam pertumbuhan dan perkembangan jasmani, rohani sesuai dengan penambahan umur serta pengalaman terhadap kehidupan masyarakat di sekitarnya makin berkembang dan meluas. Oleh karena itu anak membutuhkan pengetahuan tentang lingkungan sosialnya. Sebutan sebagai pengetahuan sosial atau Ilmu Pengetahuan Sosial (IPS) baru diketahui secara formal ketika manusia memasuki pendidikan di sekolah. Dengan demikian Ilmu Pengetahuan Sosial (IPS) dianggap sebagai ilmu yang mempelajari tentang manusia serta untuk mempolakan sejauh mana manusia itu berhubungan dengan orang lain dalam suatu kelompok. Pendidikan pada dasarnya merupakan proses mewariskan aspekaspek kehidupan manusia kepada keturunannya, agar memiliki apa yang sudah dimiliki oleh pendahulunya. Aspek-aspek kehidupan itu dapat berupa budaya, sosial, teknologi, kepercayaan, ilmu, cara berfikir, cara bertindak, dan cara bersikap (Hasan, tt.), agar keturunan tersebut memiliki aspek intelektual, emosional, nilai, ketrampilan, sikap, dan nurani maka terjadilah proses komunikasi dan proses pendidikan.

Proses pendidikan di berbagai Negara dapat mengalami perbedaan karena memiliki sejarah, nilai sosial-budaya, ekonomi, dan perkembangan politik, teknologi yang berbeda. Perbedaan sistem pendidikan di beberapa negara ini terletak pada penekanan variable tertentu dalam pendidikan. Dari perbedaan-perbedaan system pendidikan yang muncul di beberapa Negara ini yang melatarbelakangi lahirnya pendidikan komparatif. Pendidikan komparatif berdasarkan pada asumsi-asumsi filosofis, memandang realitas secara subjektif dan bukan objek yang tunggal. Persoalan-persoalan epistemologis dan aksiologi menjadi pembicaraan yang penting dalam pendidikan komparatif. Sementara itu, penelitian tentang pendidikan komparatif banyak memfokuskan pada aspek geografis. Pendidikan komparatif saat itu hanya difokuskan di negara-negara maju. Jika dilihat dari tema sifat dan pendekatan metodologis, terdapat perbedaan dalam sejarahnya di berbagai belahan dunia. (Bray, Adamson \& Mason, 2007: 1-3). 
Mengetahui perbedaan dan perbandingan sistem pendidikan antar Negara dimaksudkan untuk mengetahui hal-hal apa yang akan dipertimbangkan sehubungan dengan penentuan suatu system pendidikan. Sejalan dengan pendapat Kendall dan Nicholas Hanc yang dikutip Nur (2002:4) yang menjelaskan bahwa tujuan perbandingan pendidikan adalah untuk mengetahui prinsip-prinsip apa yang sesungguhnya mendasari pengaturan perkembangan pendidikan nasional. Sistem pendidikan di dalamnya terdapat berbagai unsur yang saling berkaitan di antaranya adalah kurikulum. Posisi kurikulum dalam sistem pendidikan sangat penting, sebab di dalamnya terdapat visi dan tujuan pendidikan suatu Negara.

Masing-masing Negara yang berbeda tentu saja akan memiliki perberbedaan pula pandangannya mengenai tujuan. Thut dan Adams (2005: 6) bahwa program pendidikan formal diselenggarakan secara sadar untuk mewujudkan pemikiran sosial dan nilai khusus yang dipegang oleh suatu masyarakat. Bahkan pada masyarakat yang primitif sekalipun, sistem pendidikan diselenggarakan memiliki tujuan, mengapa mereka melakukannya. Selanjutnya menurut Thut dan Adam (2005) bahwa ketika mereka melakukan pilihan terhadap institusi, kurikulum dan praktik pendidikan, bukanlah sebuah kebetulan belaka, tetapi hasil pemikiran dengan orientasi kebangsaan yang jelas dan dilakukan secara sadar.

Kontak antar negara dalam bentuk kerja sama pengembangan pendidikan secara langsung maupun tidak langsung akan sangat bermanfaat untuk memperluas cakrawala terhadap pendidikan nasional dan diharapkan dapat mengambil nilai-nilai positif dari negara tertentu untuk menunjang usaha peningkatan kualitas pendidikan nasional. Indonesia yang terlalu lama dijajah oleh Belanda, sedang Malaysia, dan Hong Kong adalah Negara bekas jajahan Inggris secara sosial historis memiliki perkembangan yang berbeda dalam dunia pendidikan. Perbedaan tersebut dapat dilihat dari apa yang telah dicapai dari masing-masing Negara (Hong Kong merupakan daerah otonom bagian dari RRC) saat ini. Inilah yang mendasari penulis untuk melakukan studi komparatif, terutama Ilmu Pengetahuan Sosial (IPS) Sekolah Dasar di Indoneisa, Malaysia, dan Hong Kong.

\section{Sistem Pendidikan dan Ilmu Pengetahuan Sosial di Indonesia}

Akar sistem pendidikan yang berlaku di Indonesia, setidaknya terpengaruh oleh warisan kolonial Belanda. Namun, meskipun pengaruh penjajahan Belanda di Indonesia telah berlangsung selama tiga setengah abad, justru sistem pendidikan yang banyak digunakan adalah masa pendudukan Jepang. Misalnya 
dalam sistem penjenjangan pendidikan di Indonesia pasca kemerdekaan. Ketika akhir pendudukan Jepang, pola sistem penjenjangan yang berlaku adalah 6-3-3-4, begitu Indonesia merdeka ternyata sistem penjenjangan ini diteruskan dengan menerapkan 6 tahun bagi SD, 3 tahun bagi SMP, 3 tahun bagi SMA, dan 4 tahun sampai 6 tahun bagi perguruan tinggi. Tentu saja dengan menyebut kolonial tersebut bukan menunjukkan totalitas karena terlalu banyaknya perbedaan yang dikembangkan oleh negara bersangkutan setelah merdeka. Pasca kemerdekaan, sistem pendidikan di Indonesia mengalami serangkaian transformasi dari sistem persekolahannya (Assegaf, 2003: 267-268). Hal ini bisa dilihat dengan adanya perubahan undang-undang tentang pendidikan, yaitu UU No.4 Tahun 1950 tentang dasar-dasar pendidikan dan pengajaran di sekolah untuk seluruh Indonesia dan UU No.2 Tahun 1989 tentang Sistem Pendidikan Nasional. Melalui undangundang ini, maka pendidikan nasional telah mempunyai dasar legalitasnya. Namun demikian pendidikan nasional sebagai suatu sistem bukanlah merupakan suatu hal yang baku. Suatu sistem merupakan suatu proses yang terusmenerus mencari dan menyempurnakan bentuknya (Tilaar, 1999: 1).

Dalam Undang-undang Sisdiknas Tahun 2003 disebutkan bahwa, pendidikan nasional berfungsi mengembangkan kemampuan dan membentuk watak serta peradaban bangsa yang bermartabat dalam rangka mencerdaskan kehidupan bangsa, bertujuan untuk berkembangnya potensi peserta didik agar menjadi manusia yang beriman dan bertakwa kepada Tuhan Yang Maha Esa, berakhlak mulia, sehat, berilmu, cakap, kreatif, mandiri, dan menjadi warga negara yang demokratis serta bertanggung jawab.

IPS adalah suatu bahan kajian yang terpadu yang merupakan penyederhanaan, adaptasi, seleksi, dan modifikasi yang diorganisasikan dari konsep-konsep dan keterampilan-keterampilan Sejarah, Geografi, Sosiologi, Antropologi, dan Ekonomi (Sriyanto, 2014b; Puskur, 2001 : 9). Materi pelajaran IPS merupakan penggunaan konsep-konsep dari ilmu sosial yang terintegrasi dalam tema-tema tertentu. Skeel (1995: 11) menjelaskan bahwa IPS (social studies) bertujuan untuk membantu mengembangkan konsep diri dengan baik, bagaimana menjadi bagian dari masyarakat global dan multikultur, proses sosialisasi ekonomi, politik dan sosial, membangun pengetahuan tentang masa lalu dan sekarang sebagai dasar untuk pengambilan keputusan, membangun keterampilan problem-solving.

IPS menggambarkan interaksi individu atau kelompok dalam masyarakat baik dalam lingkungan fisik dan lingkungan sosial. Interaksi antar individu dalam ruang lingkup lingkungan 
mulai dari yang terkecil misalkan keluarga, tetangga, rukun tetangga atau rukun warga, desa/kelurahan, kecamatan, kabupaten, provinsi, negara dan dunia. Karakteristik tujuan IPS menurut Bruce Joyce (Sriyanto, 2014b; Kenworthy, 1981 : 7) memiliki tiga katagori yaitu: 1. Pendidikan kemanusiaan. 2. Pendidikan kewarganegaraan. 3. Pendidikan intelektual. Pendidikan kemanusiaan memiliki arti bahwa IPS harus membantu anak memahami pengalamannya dan menemukan arti atau makna dalam kehidupannya. Dalam tujuan pertama ini terkandung unsur pendidikan nilai. Pendidikan kewarganegaraan mengandung arti bahwa peserta didik harus dipersiapkan untuk berpartisipasi secara efektif dalam dinamika kehidupan masyarakat. Peserta didik memiliki kesadaran untuk meningkatkan prestasinya sebagai bentuk tanggung jawab warga negara yang setia pada negara. Pendidikan nilai dalam tujuan ini lebih ditekankan pada kewarganegaraan. Pendidikan intelektual mengandung arti bahwa anak membutuhkan untuk memperoleh ide-ide yang analitis dan alatalat untuk memecahkan masalah yang dikembangkan dari konsep-konsep ilmu sosial (Puskur, 2007: 14-15). Menurut Barr, Barth, dan Shermis (1978) social studies taught as citizenship transmission, social studies taught as social sciences, social studies as reflective inquiry (lihat juga Chapin dan Messick, 1989: 6-
7). Materi IPS dapat diorganisasikan ke dalam bentuk yang terpisah-pisah (separated), korelasi (corelated), dan fusi (integrated).

Nama IPS dalam dunia pendidikan dasar di Indonesia muncul bersamaan dengan diberlakukannya kurikulum SD, SMP dan SMU tahun 1975. Dilihat dari sisi keberlakuannya, IPS disebut sebagai bidang studi "baru", karena cara pandangnya bersifat terpadu. Hal tersebut mengandung arti bahwa IPS bagi pendidikan dasar dan menengah merupakan hasil perpaduan dari mata pelajaran geografi, ekonomi, ilmu politik, ilmu hukum, sejarah, antropologi, psikologi, dan sosiologi. Perpaduan ini disebabkan mata pelajaran tersebut memiliki objek material kajian yang sama yaitu manusia (Taneo, 2005, Sriyanto, 2014a). Dalam kurikulum sekolah tersebut tercantum bidang studi IPS yang merupakan perpaduan dari sejarah, geografi dan ekonomi; mulai dari SD sampai Sekolah Menengah. Dalam bidang pengetahuan sosial, dikenal banyak istilah yang kadang-kadang dapat mengacaukan pemahaman. Istilah tersebut meliputi Ilmu Sosial (Social Sciences), Studi Sosial (Social Studies) dan Ilmu Pengetahuan Sosial (IPS).

Tujuan umum pendidikan SD menurut kurikulum 1975 adalah agar lulusan: Memiliki sifat-sifat dasar sebagai warga negara yang baik; Sehat jasmani dan rohani; Memiliki pengetahuan, keterampilan, dan sikap dasar yang 
diperlukan untuk: melanjutkan pelajaran; bekerja di masyarakat; mengembangkan diri sesuai dengan azas pendidikan seumur hidup. Bidang studi Ilmu Pengetahuan Sosial (IPS) pada kurikulum 1975 dimulai dari kelas III - VI sebanyak 2 jam pelajaran (Depdikbud, 1976).

Pada Kurikulum 1984, pengajaran IPS terpadu hanya dilaksanakan di SD, sedangkan di SMP digunakan pendekatan IPS Terkait (korelasi), dan untuk SMA tidak lagi dikenal IPS terpadu melainkan diajarkan secara terpisah sehingga muncullah mata pelajaran sejarah, geografi, ekonomi, antropologi, sosiologi dan tata negara yang berdiri sendiri. Bidang studi IPS kurikulum 1984 diberikan mulai kelas III-VI dengan pembagian 2 jam pelajaran untuk kelas III, dan 3 jam pelajaran untuk kelas IV-VI (Pusatbangkurrandik, Depdikbud, 1984).

Menurut Kurikulum 1994, program pengajaran IPS di SD terdiri dari IPS Terpadu dan Sejarah Nasional. IPS terpadu adalah pengetahuan yang bersumber dari geografi, ekonomi, sosiologi, antropologi dan ilmu politik yang mengupas tentang berbagai kenyataan dan gejala dalam kehidupan sehari-hari. Sedangkan Sejarah Nasional adalah pengetahuan mengenai proses perkembangan masyarakat Indonesia dari masa lampau sampai dengan masa kini. Untuk tingkat SMP, IPS hanya mencakup bahan kajian geografi, ekonomi, dan sejarah. Khusus mata pelajaran sejarah mencakup materi yang lebih luas yakni mengenai proses perkembangan masyarakat Indonesia dan masyarakat dunia sejak masa lampau hingga sekarang. Sedangkan untuk SMA, IPS tetap diajarkan secara terpisah atau berdiri sendiri.

Pendidikan dasar (SD dan SLTP atau sekolah lanjutan tingkat pertama) bertujuan memberikan bekal kemampuan dasar kepada siswa untuk mengembangkan kehidupannya sebagai pribadi, anggota masyrakat, warga negara dan anggota umat manusia serta mempersiapkan siswa untuk mengikuti pendidikan menengah (Pasal 3 Peraturan Pemerintah No. 28 Tahun 1990 tentang Pendidikan Dasar). Pendidikan dasar yang diselenggarakan di sekolah dasar (SD) bertujuan memberikan bekal kemampuan dasar "BacaTulis-Hitung”, pengetahuan dan keterampilan dasar yang bermanfaat bagi siswa sesuai dengan tingkat perkembangannya serta mempersiapkan mereka untuk mengikuti pendidikan di SLTP. Kurikulum 1994 IPS diberikan dari kelas III-VI, dengan pembagian kelas III sebanyak 3 jam, kelas IV-VI sebanyak 5 jam pelajaran (Depdikbud, 1993).

Pemikiran yang melandasi mengenai pengembangan kurikulum 2004 tidak dapat dilepaskan dengan konteks reformasi pendidikan nasional yang ditandai dengan diberlakukannya Undang-Undang Nomo: 20 Tahun 2003 Tentang Sistem Pendidikan Nasional. Undang-undang 
tersebut menjadi acuan dan sumber mereformasi pendidikan nasional yang mencakup seluruh komponen dalam system pendidikan nasional, termasuk kurikulum. Reformasi pendidikan tersebut dinyatakan sebagai berikut. Gerakan reformasi di Indonesia secara umum menuntut diterapkannya prinsip demokrasi, desentralisasi, keadilan, dan menjunjung tinggi hak asasi manusia dalam kehidupan berbangsa dan bernegara. Dalam hubungannya dengan pendidikan, prinsip-prinsip tersebut akan memberikan dampak yang mendasar pada kandungan proses, dan manajemen sistem pendidikan. Selain itu, ilmu pengetahuan dan teknologi berkembang pesat dan memunculkan tuntutan baru dalam segala aspek kehidupan, termasuk dalam sistem pendidikan (Soedijarto, et.al., 2010: 90; lihat juga Hasan, tt.).

Kurikulum 2004 yang lebih dikenal dengan Kurikulum Berbasis Kompetensi (KBK), belum sempat ditetapkan sebagai kurikulum secara nasional, tahun 2006 lahir kurikulum sebagai penyempurnaan KBK yang dikenal dengan Kurikulum Tingkat Satuan Pendidikan (KTSP). Mata pelajaran IPS pada kurikulum ini di kelas I-III tidak berdiri sendiri tetapi dalam bentuk tematik, sehingga IPS sebagai mata pelajaran sendiri baru diberikan dari kelas IV samapi kelas 6 sebanyak 3 jam pelajaran.

Sistem Pendidikan dan Kajian Tempatan di Malaysia
India dan Malaysia merupakan contoh bagi hadirnya pengaruh sistem pendidikan kolonial Inggris atas kelanjutan sistem pendidikanyang berlaku di kedua Negara tersebut. beberapa praktek pendidikan yang dilaksanakan Inggris ternyata diteruskan, bisa jadi karena dianggap masih relevan, baik oleh India maupun Malaysia. Malaysia terdiri daripada dua kawasan utama yang dipisahkan oleh Laut China Selatan (531.1 kilometer persegi). Iklimnya ialah khatulistiwa, dan sebagian Malaysia, terutamanya di bahagian utara Semenanjung Malaysia dan utara Sabah mengalami iklim monsun tropik. Luas Semenanjung Malaysia, 131,598km² berbatasan dengan Thailand di utara dan Singapura di selatan, Sabah seluas $73,711 \mathrm{~km}^{2}$, dan Sarawak. Malaysia terbahagi kepada 13 negeri dan 3 wilayah persekutuan. Negeri yang terbesar adalah Sarawak, melebihi 124,000km², Pahang yang mempunyai luas $35,965 \mathrm{~km}^{2}$ merupakan negeri yang terbesar di Semenanjung Malaysia. Putrajaya ialah pusat pemerintahan yang baru kerajaan persekutuan, sebagai alternative untuk mengurangi kepadatan lalu lintas di Kuala Lumpur. Sejak tahun 1999 Pejabat Perdana Menteri telah berpindah ke Putrajaya dan semua pejabat kerajaan pusat telah pindah ke Putrajaya pada 2005. (http://ms.wikipedia.org/wiki/Geografi Malaysia , 16/09/2011). 
Sebelum kedatangan Inggris, sistem pendidikan orang Melayu adalah berlandaskan kepada pelajaran agama Islam, yaitu kitab suci Al-Quran. Pendidikan yang penting saat itu ialah pendidikan Islam di mana pondok dan madrasah merupakan tempat mendapat pendidikan Islam. Sewaktu zaman penjajahan Inggris, mereka telah melaksanakan system pendidikan yang berladaskan pendidikan Inggris, di mana sekolah-sekolah yang didirikan oleh Inggris ini mengajar mata pelajaran dalam bahasa Inggris. Hal ini menimbulkan kesulitan bagi bangsa Melayu,kerana majoritas masyarakat Melayu tidak mahir untuk menggunakan bahasa Inggris dengan baik. Tujuan penggunaan bahasa Inggris di sekolah ini adalah untuk membatasi bangsa Melayu belajar di sekolah Inggris, sebab jika bangsa Melayu pandai, ia akan membuat kedudukan Inggris terancam (Sufean Hussin,dalam Mior Khairul Azrin Bin Mior Jamaluddin: 2011: 34-35). Hanya pelajar Melayu dari kelas atasan saja yang diberi peluang untuk belajar di sekolah Inggeris.

Pada zaman penjajahan ini, dasar pendidikan - terutama sistem persekolahan tidak memberikan sumbangan yang positif, sebab tujuan Inggris hanya mementingkan keuntungan ekonomi dan kedudukan.Pada masa itu juga Inggris membuka sekolah untuk bangsa Cina, dan India. Berdirinya sekolah khusus untuk orang Cina dan India ini menyebabkan hubungan mereka menjadi semakin renggang. Tujuan system persekolahn ini adalah sekolah Melayu untuk kepentingan orang Melayu, sekolah Cina untuk kepentingan orang Cina, dan sekolah Tamil untuk kepentingan orang India. Sekolah Cina mendapat keistimewaan melalui sekolah rendah (6 tahun), junior middle (3 tahun), dan senior middle (3 tahun), sedangkan sekolah Melayu dan Tamil hanya Setingkat sekolah rendah. Maka, sistem pendidikan penjajahan Inggris itu adalah: (1) Sekolah Pondok dan Madrasah, (2) Sekolah Melayu, (3) Sekolah Cina, (4) Sekolah Tamil, dan (5) Sekolah Inggeris (Mior Khairul Azrin Bin Mior Jamaluddin: 2011: 36).

Setelah merdeka, Malaysia menyusun rancangan pendidikan tahun 1971 - 1975 ditetapkan pada tiga bidang,yaitu: menyatukan sistem pelajaran untuk memperkuat perpaduan negara, (2) memperluas rancangan pelajaran bagi mencapai keperluan negara mengenai tenaga rakyat, dan (3) memperbaiki mutu pelajaran ke arah mencapai masyarakat yang maju berdasarkan sains dan teknologi modern, untuk mewujudkan Dasar Ekonomi Baru (DEB). Untuk mewujudkan rencana itu, strategi yang dipergunakan adalah menggunakan Bahasa Malayu sebagai bahasa pengantar utama di semua sekolah secara berperingkat, mengurangkan jurang perbedaan mendapatkan pelajaran di seluruh kawasan dan semua rakyat 
melalui pembinaan sekolah dan kemudahan sekolah, dan meningkatkan mutu pelajaran (Mior Khairul Azrin Bin Mior Jamaluddin: 2011: 36). Pada tahun 1983, kerajaan Malaysia telah wujudkan rancangan Kurikulum Baru Sekolah Rendah (KBSR) untuk dilaksanakan di semua sekolah rendah seluruh negara; dan tahun 1989 kerajaan melaksanakan rancangan Kurikulum Bersepadu Sekolah Menengah (KBSM) di semua sekolah menengah seluruh Malaysia. Keduanya KBSR dan KBSM mempunyai tujuan yang sama, yaitu sebagai alat perpaduan kaum dan negara. Setelah DEB (1971-1990), rencana selanjutnya adalah pembentukan Dasar Pembangunan Negara (DPN), 1991-2000, dalam rancangan ini sector pendidikan, kerajaan bertujuan untuk menjadikan sistem pendidikan Malaysia bertaraf dunia. Dasar Wawasan Negara (2001-hingga sekarang), Pada zaman ini Sistem Pendidikan Kebangsaan dikemas sejajar dengan perkembangan dunia teknologi. Berdasarkan perubahan dan perkembangan abad ke-21, sistem pendidikan posisinya dimantapkan dalam perundangan, dasar dan program utama, antaranya: Akta Pendidikan 1996 (Pindaan 2002); Program Bimbingan dan (Keputusan Jemaah Menteri, 2002); Pengajaran dan Pembelajaran Sains dan Matematik dalam Bahasa Inggris dilaksanakan pada tahun 2003 (Keputusan Jemaah Menteri, 2002) (http://kulanzsalleh.com/sejarah-perkembangansistem-pendidikan-di-malaysia/ , 26/09/2011).

Kementerian Pendidikan Malaysia memainkan peranan yang sangat penting dalam membawa perubahan pendidikan di Malaysia saat ini. Misi Kementerian Pendidikan Malaysia ialah membangunkan sistem pendidikan yang berkualitas dan bertaraf dunia, di samping memperkembangkan potensi individu sepenuhnya dan memenuhi aspirasi negara. Kementerian Pendidikan Malaysia menetapkan keputusan, iaitu melahirkan bangsa Malaysia yang taat setia, bersatu padu, beriman, berakhlak mulia, berilmu, berketerampilan, sejahtera, menyediakan sumber tenaga manusia untuk keperluan kemajuan negara, dan memberi peluang-peluang pendidikan kepada semua warganegara.

Pendidikan di Malaysia secara keseluruhan dibawah hukum Kementrian Pendidikan, yang bertanggung jawab mengurusi sistem pendidikan dari tingkat dasar sampai dengan universitas, mengatur silabus, mengontrol ujian nasional dan mengawasi perkembangan pendidikan. Pendidikan dasar di Malaysia berlangsung selama enam tahun. Pendidikan tersebut ditujukan untuk memberikan pendidikan dasar bagi siswa agar menguasai kompetensi membaca, menulis dan aritmatik. Pada akhir tahun ajaran siswa sekolah akan diuji yang disebut dengan Ujian Penilaian Sekolah 
Rendah/ The Primary school Assessment Test (UPSR/PSAT). Terlepas dari kinerja mereka di PSAT, semua siswa sekolah dasar dinaikkan ke Form one. Pendidikan sekolah menengah adalah kelanjutan dari level pendidikan dasar. Silabus, Kurikulum Bersepaduan Sekolah Menengah/ Secondary School Integrated Curriculum (KBSM/SSIC) dikembangkan untuk menyesuaikan kebutuhan dan aspirasi Negara. Pendidikan menengah dibagi ke dalam tiga level utama: lower secondary level, upper secondary level dan level pra universitas.

Lower secondary education di Malaysia mempersiapkan siswa untuk mengembangkan keterampilan yang dibutuhkan di dalam kehidupan dan dapat menjadi warga Negara yang berguna bagi Negara. Setelah menyelesaikan tahun ketiga, para siswa diharuskan untuk mengikuti ujian penilaian nasional, Penilaian Menengah Rendah/Lower Secondary Assessment (PMR/LSA). Kinerja siswa pada PMR/LSA akan menentukan jurusan akademik mereka kepada upper secondary level, yaitu apakah akan dijurusan sain, seni, teknik atau vokasional.

Pemilihan siswa dan jurusan akademik pada upper secondary level akan ditentukan oleh Kemetrian Pendidikan. Pada akhir masa pendidikan dua tahun di pendidikan upper education, siswa akan diuji oleh ujian nasional wajib, Sijil Pelajaran Malaysia/ Malaysia Certificate of Examination (SPM/MCE) atau
Sijil Pelajaran Malaysia Vokasional/ Vocational Malaysian Certificate (SPM/VMCE), kalau siswa memilih jurusan vokasional. Sertifikat SPM/MCE/SPMV/VMCE sama dengan O-level Cambridge University Examinations.

Siswa pada jurusan vokasional akan mempelajari bidang studi vokasional yang berhubungan dengan bidang studi lain yang identik kepada silabus sekolah umum lainnya. Mereka diharuskan untuk mengikuti Peperiksaan Sijil Pelajajran Malaysia Vokasional (SPMV) pada akhir tahun ajaran kedua. Bagi siswa yang mempunyai hasil yang baik bisa melanjutkan studi mereka ke lembaga pendidikan tinggi local atau langsung masuk ke pasar kerja. Kursurs Pelatihan Keterampilan (Skills Traning Course) adalah program tambahan. Siswa akan melalui program pelatihan keterampilan dengan demikian memungkinkan mereka untuk mengikuti Peperiksaan Majilis Latihan Vokasional Kebangsaan Asa (MLVK) pada dua tahun akhir program pendidikan. Mereka kemudian akan bergabung dengan pasar kerja atau melalui pelatihan keterampilan tingkat atas (advance skills training) diwalau tertentu. Pelatihan vokasional bagi pemuda penting bagi perkembangan nasional. Selain kemetrian pendidikan masih ada kementrian lain, agen public atau swasta terlibat didalam pelatihan vokasional bagi pemuda untuk mengisi kebutuhan tenaga kerja indrustri . Pada program 
pendidikan pra-universita diklasifikasi kedalam dua kelompok yaitu A Level dan program studi matrikulasi. Yang masuk pada program ini didasarkan pada hasil kinerja (SPM/SPMV). Untuk program studi A Level, jurusan pendidikannya adalah kesenian, sain dan teknik. Siswa akan diharuskan untuk mengikuti Sijil Tinggi Pelajaran Malaysia Examination (STPM), yang diatur oleh Dewan Ujian Malaysia dan diakreditasikan oleh University of Cambridge Local examination Syndicate of England (UCLES). Kualifikasinya di atur oleh banyak universitas di dunia. Program studi matrikulasi yang diatur calon mahasisa pada universitas lokal. Ini merupakan program dasar akademik satu tahun, dimonitor oleh universitas tuan rumah dan pembelajaran dilaksanakan di masing-masing sekolah negeri atau swasta.

Pada era tahun 70an sampai 80an keadaan pendidikan di Indonesia masih di atas Malaysia. Orang Malaysia datang belajar ke Indonesia. Bahkan beberapa guru dari Indonesia diperbantukan mengajar di Malaysia. Sekarang pendidikan di Malaysia termasuk yang paling baik di dunia, tetapi Indonesia malah terkesan berjalan di tempat. Tambahan lagi sekarang biaya pendidikan sudah mulai menjadi di luar jangkauan kebanyakan masyarakat di Indonesia.

Sistem pendidikan di Malaysia disusun berdasarkan pada Sistem Pendidikan Inggris. Pendidikan rendah atau pendidikan dasar di
Malaysia dimulai pada kanak-kanak usia $7-12$ tahun (pendidikan dasar 6 tahun).

Kurikulum Kajian Tempatan (Sejarah dan Geografi) yang terangkum dalam bidang kemanusiaan dan kemasyarakatan bertujuan membentuk rakyat Malaysia yang bersatu padu, hidup dalam masyarakat yang mempunyai nilai moral dan etika yang utuh, mengamalkan demokrasi, penyayang, progresif, sejahtera serta bersemangat patriotik. Selaras dengan kehendak Falsafah Pendidikan Kebangsaan, kurikulum Kajian Tempatan ini dapat melahirkan insan yang berilmu dan beramal, harmonis serta berketrampilan. Mata pelajaran ini juga disesuaian dengan struktur Kurikulum Bersepadu Sekolah Rendah ( KBSR ). Kajian Tempatan merupakan mata pelajaran yang membicarakan dan mengkaji tentang interaksi manusia dengan manusia dan manusia dengan alam sekitarannya melalui aktivitas pembelajaran, kemampuan berfikir dan keterampilan social. Mata pelajaran ini diajar secara formal di Tahap II untuk memperkuat pengetahuan, pemahaman, kemamapuan dan keterampilan, kesadaran dan nilai yang telah dipadukan secara terencana dalam mata pelajaran lain di Tahap I terutama mata pelajaran bahasa.

Kurikulum Kajian Tempatan bertujuan melahirkan murid yang setia pada negara, cinta akan tanah air, prihatin dan berbangga sebagai rakyat Malaysia serta berinteraksi secara baik 
untuk mewujudkan masyarakat Malaysia yang harmonis, bersatu padu, demokratik, progresif dan sentiasa mensyukuri nikmat Tuhan. Organisasi kurikulum Sukatan Pelajaran Kajian Tempatan ini terdiri dari program pembelajaran untuk tiga tahun mulai Tahun 4 hingga Tahun 6 . Kandungan mata pelajaran ini diolah mencakup tiga ruang lingkup yaitu: pertama keluarga, rumah, jiran dan sekolah; kedua kawasan tempat tinggal, mukim, daerah / jajahan, bahagian dan negeri; ketiga Negara (Malaysia).

\section{Sistem Pendidikan dan Social Studies di Hong Kong}

Kajian terhadap perkembangan pendidikan social studies di Hong Kong menjadi amat menarik. Pertama, sebagai bekas 'negara kota $^{e}$ jajahan Inggris, Hong Kong mengalami satu pergeseran identitas politik dari wilayah koloni menjadi kesatuan wilayah berdaulat di bawah pemerintah China Daratan (Republik Rakyat China, RRC). Hal ini membawa akibat pada status Hong Kong sebagai daerah pemerintah khusus di dalam negara RRC yang dikenal sebagai, 'One Country, Two Systems.' (Joe Tin-yau LO, 2002). Kedua, perubahan identitas politik tadi mempengaruhi sistem politik yang pada masa kolonial Inggris, Hong Kong begitu kuat ditanamkan arti penting prinsip-prinsip pemerintahan demokrasi liberal model Inggris. Namun, setelah penyerahan kedaulatan Hong Kong kepada RRC, maka berdampak pada proses politik yang mengikuti budaya politik China yang dominan dipengaruhi Konfusianisme.

Pada 1 Juli 1997 Hong Kong diserahkan kembali kepada RRC setelah sekitar satu setengah abad menjadi salah satu koloni Inggris. Dalam waktu yang lama, sejarah kolonial di Hong Kong ditandai oleh sebuah strategi depolitisasi dari pemerintah Inggris, dan warga negara menjadi apolitis (Lee, 1999: 314).

Menurut Lee Wing On (1999: 314), ada dua alasan utama menjadikan karakteristik depolitisasi Hong Kong tersebut. Pertama, secara geografis Hong Kong lebih dekat dibanding Inggris, dan China memiliki pengaruh kuat terutama dalam arti suplai pangan dan air serta kontrol terhadap arus pengungsi dan imigran. Kondisi ini mengakibat berpengaruh secara politik terhadap Hong Kong. Kedua, Hong Kong sendiri adalah sebuah wilayah imigran yang secara luas terdiri atas para pengungsi China. Ini mengakibatkan rakyat awam Hong Kong menjaga jarak dengan pemerintah dan badan peradilan bahkan menghindari sejauh mungkin kecendrungan politik akibat pengungsian itu. Pada gilirannya warga Hong Kong lebih memfokuskan diri kepada kegiatan-kegiatan ekonomi.

Social studies, yang diajarkan di sekolahsekolah sejak pertama ditawarkan pada 1950. 
Pada 1952, kajian civics bersama-sama geografi dan sejarah membentuk mata pelajaran baru yang disebut social studies di dalam kurikulum sekolah dasar (Lee, 1999:315). Civics diajarkan sebagai mata pelajaran tersendiri di sekolah menengah pertama hingga kemudian diganti oleh mata pelajaran economic and public affairs (EPA) pada 1965. Selanjutnya pada 1980an silabus EPA direvisi dengan tekanan pada, individual and society dan, enhancement of political awareness (Lee, 1999: 315). Pada 1972 di dalam social studies dikenalkan kajian government di tingkat sekolah menengah pertama, yang membahas topik hubungan antara individu dan masyarakat sama halnya dengan peran warga Negara di tingkat masyarakat local dan internasional. Social studies kemudian diperluas untuk tingkat sekolah menengah atas pada tahun 1984 (Lee, 1999:315-316).

Secara umum kurikulum pendidikan di Hong Kong pasca 1997 antara lain meliputi pelajaran sebagai berikut: Chinese Language Education; English Language Education; Mathematics Education; Science Education; Technology Education; Personal, Social and Humanities Education (PSHE);Arts Education; Physical Education (Tammy Kwan, 2003: 67).

Kaitannya dengan civic education di lingkungan sekolah di Hong Kong pasca 1997, pemerintah setempat makin meningkatkan unsurunsur ke-China-an dalam kurikulum sekolah,
Sebagai contoh, sejarah dan budaya China dirancang sebagai unsur pokok (core elements) pembelajaran dengan nama baru: Personal, Social and Humanities Education (PSHE). Lebih dari itu, kegiatan-kegiatan ekstrakurikuler dikaitkan dengan budaya China seperti orkestra China, tarian China, dan kelas-kelas Kung Fu, menjadi intensif (Lee, 2006: 4). Sebagai gambaran kompetensi dasar PSHE di tiap jenjang sekolah (dasar hingga menengah atas) dijabarkan dalam Tabel 1. Dari tabel tersebut tampak jelas bahwa konsep nasionalisme dan moralitas (konfusianisme) dalam PSHE menjadi dasar bagi civic education di Hong Kong. Selain itu, PSHE ini memuat aspek-aspek kajian secara integratif bagi mata pelajaran lainnya yang menjadi etos pembelajaran sepanjang hayat.

Hong Kong menggunakan kurikulum untuk pendidikan social General Studies Syllabus sebagai pedoman untuk Primary Schools (primary 1 - primary 6). Termasuk di dalamnya adalah tema-tema hidup sehat, lingkungan hidup, ilmu pengetahuan dan teknologi, dan alam sekitar. (Joe Tin-yau LO, 1999). Kurikulum social studies di Hong Kong telah mengalami beberapa pergantian di antaranya pada tahun 1967 social studies syllabus, masa ini Hong Kong masih berada di bawah koloni Inggris, kemudian tahun 1980 social studies syllabus, dan tahun 1997 berubah menjadi general studies syllabus (LO, 1999). 
Menuru Joe Tin-yua LO, kurikulum di Hong Kong dengan demikian lebih menggunakan pendekatan cross-disciplinary, sebab "Hong Kong's general studies is more like a hotchpotch of moral/civic education, sex education, environmental education, technology education and health education" (LO, 2002). General studies di Hong Kong merupakan integrasi masyarakat-teknologi-ilmu pengetahuan, sehingga objek yang hendak dicapai adalah pengetahuan, keterampilan, nilai.

\section{Perbandingan IPS Sekolah Dasar di}

\section{Indonesia, Malaysia, dan Hong Kong}

Kedudukan pengajaran IPS begitu unik karena harus mempersiapkan dan mendidik anak didik untuk hidup dan memahami dunianya, dimana kualitas personal dan kualitas sosial seseorang akan menjadi hal yang sangat vital. Menurut A.K. Ellis (1991), bahwa alasan dibalik diajarkannya IPS sebagai mata pelajaran di sekolah karena hal-hal sebagai berikut:

a) IPS memberikan tempat bagi siswa untuk belajar dan mempraktikan demokrasi.

a) IPS dirancang untuk membantu siswa menjelaskan "dunianya".

b) IPS adalah sarana untuk pengembangan diri siswa secara positif.

c) IPS membantu siswa memperoleh pemahaman mendasar (fundamental understanding) tentang sejarah, geographi, dan ilmu-ilmu sosial lainnya.

d) IPS meningkatkan kepekaan siswa terhadap masalah-masalah sosial.

Barr et. al (Nelson, 1987; Chapin dan Messick,1996) merumuskan tiga perspektif tradisi utama dalam IPS. Ketiga tradisi utama tersebut ialah:

a) IPS diajarkan sebagai pewarisan nilai kewarganegaraan (citizenship transmission).

b) IPS diajarkan sebagai ilmu-ilmu sosial.

c) IPS diajarkan sebagai reflektif inquiry (reflective inquiry).

Tujuan pendidikan IPS di tingkat Sekolah Dasar (SD) ditujukan untuk mengembangkan pengetahuan dan ketrampilan dasar siswa yang berguna untuk kehidupan sehari harinya. IPS sangat erat kaitannya dengan persiapan anak didik untuk berperan aktif atau berpartisipasi dalam pembangunan Indonesia dan terlibat dalam pergaulan masyarakat dunia (global society). IPS harus dilihat sebagai suatu komponen penting dari keseluruhan pendidikan kepada anak. IPS memerankan peranan yang signifikan dalam mengarahkan dan membimbing anak didik pada nilai-nilai dan perilaku yang demokratis, memahami dirinya dalam konteks kehidupan masa kini, memahami tanggung 
jawabnya sebagai bagian dari masyarakat global yang interdependen (Permendiknas No. 22. 2006).

Kurikulum Kajian Tempatan bertujuan melahirkan murid yang setia pada negara, cinta akan tanah air, prihatin dan berbangga sebagai rakyat Malaysia serta berinteraksi secara baik untuk mewujudkan masyarakat Malaysia yang harmonis, bersatu padu, demokratik, progresif dan sentiasa mensyukuri nikmat Tuhan. (Pusat Perkembangan Kurikulum, Kementrian Pendidikan, 2001).

Di Hong Kong social studies masuk dalam kelompok Personal, Social and Humanities Education dengan sebutan General Studies Curriculum unutk tingkat primary school. Mata pelajaran ini pada dasarnya memiliki tujuan untuk membentuk siswa agar memiliki pengetahuan, (knowledge), generic skills, values and attitudes. Kurikulum ini kontennya meliputi: Health and Living, People and Environment, Science and Technology in Everyday Life, Community and Citizenship, National Identity and Chinese Culture, Global Understanding and the Information Era (The Curriculum Development Council, 2011).

Perbandingan Pendidikan IPS untuk sekolah dasar di ketiga Negara tersebut seperti termuat dalam table berikut ini:

\begin{tabular}{|c|c|c|}
\hline No & Uraian & Indonesia \\
\hline 1 & $\begin{array}{l}\text { Tema IPS } \\
\text { Kelas } 1-3\end{array}$ & $\begin{array}{lr}\text { Tematik: } & \text { Identitas diri } \\
\text { dan } & \text { keluarga; }\end{array}$ \\
\hline
\end{tabular}

\begin{tabular}{|c|c|c|c|}
\hline & & $\begin{array}{ll}\text { Lingkungan } & \text { Keluarga } \\
\text { dan sekolah } & \end{array}$ & \\
\hline 2 & $\begin{array}{l}\text { Tema } \\
\text { Kelas } 4\end{array}$ & $\begin{array}{l}\text { Alam dan Potensi } \\
\text { Daerahku; } \\
\text { Kesejahteraan } \\
\text { Masyarakat Daerahku }\end{array}$ & $\begin{array}{l}\text { Keluarga, r } \\
\text { jiran dan } \\
\text { sekolah. }\end{array}$ \\
\hline 3 & $\begin{array}{l}\text { Tema } \\
\text { Kelas } 5\end{array}$ & $\begin{array}{l}\text { Kejayaan Negeriku; } \\
\text { Tantangan Bangsaku }\end{array}$ & $\begin{array}{l}\text { Kawasan te } \\
\text { tinggal,mu } \\
\text { daerah/jaja } \\
\text { bahagian d }\end{array}$ \\
\hline 4 & $\begin{array}{l}\text { Tema } \\
\text { Kelas } 6\end{array}$ & $\begin{array}{lrr}\text { Indonesia } & \text { di } & \text { Tengah- } \\
\text { Tengah } & & \text { Dunia; } \\
\text { Indonesia } & \text { di } & \text { Era } \\
\text { Globalisasi } & & \end{array}$ & $\begin{array}{l}\text { Sumber Ne } \\
\text { Ekonomi N } \\
\text { Pembinaan } \\
\text { Bangsa Da } \\
\text { Negara; Ke } \\
\text { Dan } \\
\text { Kebanggaa } \\
\text { Negara }\end{array}$ \\
\hline
\end{tabular}

IPS di Indonesia diberikan sejak Kelas 1 - 6, dengan pembagian tema Kelas 1 - 3 menggunakan pendekatan tematik; Di Malaysia IPS diberikan mulai dari Kelas 4 dengan nama mata pelajaran Kajian Tempatan; sedangkan di Hong Kong, general studies diberikan sejak primary 1 (P1) sampai dengan primary 6 (P6). Di

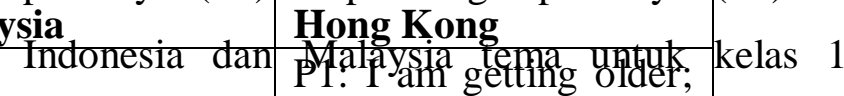
berkisar tentanglondèri xitaet (dhame;meskipun 
materi di Hong Kong sudah memasukkan materi tentang kewilayahan. Sedangkan di Malaysia materi tentang keluarga dan lingkungan sekitar diberikan pada Kelas 4. Materi Kelas 6 (P6) di Indonesia dan Hong Kong sudah memasukkan materi global, sementara di Malaysia lebih menekankan pada kebanggaan sebagai warga Negara Malaysia. Di Malaysia pemupukan jiwa patriotic memang ditanamkan semenjak dini, yang tercantum dalam kurikulum.

\section{Simpulan}

Sejarah perkembangan kurikulum di Indonesia memperlihatkan bahwa pendekatan berbasis materi dilaksanakan sejak masa penjajahan Belanda, diteruskan sampai ke alam kemerdekaan, dan baru ditinggalkan pada tahun 2004. Pendekatan berbasis kompetensi ini dianut Pusat Kurikulum Balitbang Depdiknas setelah melewati pengalaman panjang pengembangan kurikulum secara profesional sejak awal 1970-an sampai awal 2000-an.

\section{Kurikulum Sekolah Dasar (primary} shools) di Indonesia, Malaysia, dan Hong Kong Negara yang diuraikan di atas terdapat istilah yang berbeda-beda. Ilmu Pengetahuan Sosial (IPS) di Indonesia diajarkan berdasarkan ketentuan pada pendidikan dasar (SD dan SMP). Di sekolah Dasar IPS diajarkan melalui pendekatan ke dalam bentuk yang terpisah-pisah (separated), korelasi (corelated), dan fusi (integrated). Nama IPS dalam dunia pendidikan dasar di Indonesia muncul bersamaan dengan diberlakukannya kurikulum SD, SMP dan SMU tahun 1975. Dilihat dari sisi keberlakuannya, IPS disebut sebagai bidang studi "baru”, karena cara pandangnya bersifat terpadu. Hal tersebut mengandung arti bahwa IPS bagi pendidikan dasar dan menengah merupakan hasil perpaduan dari mata pelajaran geografi, ekonomi, ilmu politik, ilmu hukum, sejarah, antropologi, psikologi, dan sosiologi. Perpaduan ini disebabkan mata pelajaran tersebut memiliki objek material kajian yang sama yaitu manusia

Sedangkan istilah Sukatan Pelajaran Kajian Tempatan (Sejarah dan Geografi) dipergunakan di Malaysia untuk Sekolah Rendah. Kurikulum Kajian Tempatan bertujuan melahirkan murid yang setia pada negara, cinta akan tanah air, prihatin dan berbangga sebagai rakyat Malaysia serta boleh berinteraksi secara berkesan ke arah mewujudkan masyarakat Malaysia yang harmonis, bersatu padu, demokratik, progresif dan sentiasa mensyukuri nikmat Tuhan. Organisasi kurikulum Sukatan Pelajaran Kajian Tempatan ini mengandungi program pembelajaran untuk tiga tahun mulai Tahun 4 hingga Tahun 6.

Di Hong Kong dengan perkembangan kurikulum yang terjadi, yang semual mengacu pada kurikulum Inggris sebagai Negara induk menggunakan istilah Social Studies, namun 
semenjak tahun 1997 menggunakan general studies. Materi dalam mata pelajaran tersebut pada dasarnya memiliki persamaan yaitu mengenalkan pada diri, dan lingkungan sekitarnya, yang dimulai dari lingkungan keluarga, masyarakat, Negara, dan dunia. Social studies di Hong Kong baik sebelum maupun sesudah penyerahan kedaulatan pada 1997 pada taraf tertentu hampir memiliki persamaanpersamaan dengan kondisi yang ada di Indonesia, terutama pada masa Orde Baru. Di Hong Kong banyak menanamkan status quo pemerintah kolonial pada sebelum 1997 dan menekankan identitas nasional serta warisan kultural Hong Kong kepada China pasca 1997.

\section{Daftar Pustaka}

Assegaf, A. R., (2003). Internasionalisasi Pendidikan: Sketsa Perbandingan Pendidikan di Negara-Negara Islam dan Barat, Yogyakarta: Gama Media.

Badan Penelitian dan Pengembangan Pusat Kurikulum, (2007). Naskah Akademik Kajian Kabijakan Kurukulum Mata Pelajaran Ilmu Pengetahuan Sosial, Jakarta: Departemen Pendidikan Nasional.

Barr, R., et.al., (1978). Hakekat Studi Sosial (The Natural of Social Studies), Saduran oleh Buchori Alma \& M. Haslasgunawan Ap., Bandung: ALFABETA.
Belen, S., (2010). Sejarah Kurikulum SD di Indonesia, Jakarta: Puskur Kementrian Pendidikan Nasional.

Chapin, June R., \& Messick, Rosemary G., (1989). Elementary Social Studies, A Practic al Guide, New York \& London: Longman.

Depdikbud, (1976). Kerangka Program dan Dasar Metodik Pendidikan Moral Pancasila dalam Rangka Kurikulum 1975.

Embong, A.R., "The Role of Social Sciences in Malaysian National Development", Akademika 70 (Januari), 2007: 145 -151.

Hasan, S. H., (2011). Pendidikan Sejarah: Orientasi dan Strategi Pedagogis, Makalah disampaikan pada Konferensi Nasional Sejarah IX, Hotel Bidakara Jakarta, 5 - 7 Juli 2011.

Hasan, S. Hamid, (tt.). Perkembangan Kurikulum: Perkembangan Ideologis dan Teoritik Pedagogis (1950 - 2005), Makalah, Online, www.geocities.ws/konferensinasionalseja rah/s_hamid_hasan.pdf. [diunduh 16/07/2013].

http://f4iqun.wordpress.com/2007/05/08/mengint ip-malaysia-membangun-pendidikandasarnya/, Diunduh 16/07/2013.

http://ms.wikipedia.org/wiki/Pendidikan di_Malaysia, diunduh 16/07/2013.

(http://ms.wikipedia.org/wiki/Geografi Malaysia , diunduh 16/07/2013). 
Joe Tin-yau LO, (2002). The Primary Social Education Curricula in Hong Kong and Singapore: A Comparative Study, Hong Kong: Department of Social Sciences, The Hong Kong Institute of Education.

Joe Tin-yau LO, (tt.). Changing Features and Meanings of the Hong Kong Primary Social Studies Curriculum in 1967 1997 , Hong Kong Institute of Education.

Depdikbud, (1993). Kurikulum Pendidikan Dasar: Landasan, Program, dan Pengembangan, Jakarta: Depdikbud, 1993.

Lee Wing On, (1999), ,Controversies of Civic Education in Political Transition, ' dalam Torney-Purta, J., Schwille, J. dan Amadeo, J., Civic Education Across Countries: Twenty-four National Case Studies from the IEA Civic Education Project. Amsterdam: International Association for the Evaluation of Educational Achievement, pp. 313-340.

Lee Wing On, (2006), ,Tensions and Contentions in the Development of Citizenship Curriculum in Asian Countries,' Keynote Address presented at the CITIZED International Conference Oriel College, Oxford, 25-27 July.

Man-tak CHAN, (2005). Features of an integrated primary curriculum Hong Kong Institute of Education, Paper for presenting at the conference of "Redesigning Pedagogy: Research, Policy and Practice", Nanyang Technological University, Singapore, May 30 - June 1, 2005.

Mior Khairul Azrin Bin Mior Jamaluddin, (2011). "Sistem Pendidikan di Malaysia:
Dasar, Cabaran, dan Pelaksanaan ke Arah Perpaduan Nasional", SOSIOHUMANIKA, 4(1) 2011.

Permendiknas No. 22. Tahun 2006, Tentang Standar Isi.

Pusat Perkembangan Kurikulum (PPK), (2001). Kurikulum Bersepadu Sekolah Rendah Sukatan Pelajaran Kajian Tempatan, Kementerian Pendidikan Malaysia.

Pusat Perkembangan Kurikulum (PPK), (2002). Huraian Sukatan Pelajaran Kurikulum Bersepadu Sekolah Menengah SEJARAH Tingakatan 4, Kementerian Pendidikan Malaysia.

Pusat Perkembangan Kurikulum (PPK), (2002). Huraian Sukatan Pelajaran Kurikulum Bersepadu Sekolah Menengah SEJARAH Tingakatan1, 2, 3, Kementerian Pendidikan Malaysia.

Pusatbangkurrandik , (1984). Kurikulum 1984 SD (Sekolah Dasar): Landasan, Program, dan Pengembangan, Jakarta: Pusatbangkurrandik, Depdikbud, 1984.

Rahimah Haji Ahmad,(1998). "Educational development and reformation in Malaysia: past, present and future", Journal of Educational Administration, Vol. 36 No. 5, 1998, pp. 462-475,

Samsuri, (2007). Profil Civic Education di Hong Kong, Makalah Sekolah Pascasarjana, UPI Bandung, tidak diterbitkan.

Sejarah Perkembangan Sistem Pendidikan Di Malaysia, http://kulanzsalleh.com/sejarahperkembangan-sistem-pendidikan-dimalaysia/, diunduh 16/07/2013. 
Sriyanto, (2014a). Human, Change and urbanization: Rural Communities Dynamics as socio-cultural and economic Resources, Jurnal Dinamika Jurnal Pendidikan Dasar, Volume 6, No 1 Maret 2014, hlm 79 - 94.

Sriyanto, (2014b). Perilaku Asertif dan Kecenderungan Kenakalan Remaja Berdasarkan Pola Asuh dan Peran Media Massa, Jurnal Psikologi, Volume 41 No 1 Juni 2014, Hlm. 74-88.

Skeel, D.J., (1995). Elementary Social Studies, Challenges for Tomorrow's World, Philadelphia: Harcourt Brace College Publishers.

Soedijarto, et.al., (2010). Sejarah Pusat Kurikulum, Jakarta: Pusat Kurikulum Badan penelitian dan Pengembangan, Kementerian Pendidikan Indonesia.

Tap MPRS No. XXVII/1966 Bab II Pasal 4.

The Curriculum Development Council, (2011). General Studies for Primary Schools Curriculum Guide (Primary 1 - Primary 6), Hong Kong: The Education Bureau.

Thut, I.N., \& Adams, D., (2005). Pola-Pola Pendidikan dalam Masyarakat Kontemporer, Terjemahan SPA Teamwork, Yogyakarta: Pustaka Pelajar.

Tilaar, H.A.R. 1999. Beberapa Agenda Reformasi Pendidikan Nasional: Dalam Perspektif Abad 21, Magelang: Indonesia Tera.

Undang-Undang Republik Indonesia Nomor 20 Tahun 2003 Tentang Sistem Pendidikan Nasional (Sisdiknas), Jakarta: Sinar Grafika. 